\title{
Review Article Management of Cholelithiasis in the Diabetic Patients
}

\author{
S Y GURAYA A S MASOOD A NASIM \\ Department of Surgery. Surgical Unit I, Allama Iqbal Medical College and Jinnah Hospital, Lahore. \\ Correspondence to Dr. Salman Yousuf Guraya E-mail: drsyg7@yahoo.com
}

In the recent past, dramatic advances in research have elucidated the prognosis of gallstone disease and have permitted a more selective choice of persons for treatment based on symptom status and projected prognosis. Ultrasound - detected-incidental gallstones are infrequently clinically significant but this finding has prompted the surgeons to have a liberal attitude towards the operative indications for cholelithiasis particularly after the advent of laparoscopy. At the same time, the management of gallstones in the diabetics still remains controversial. Early retrospective studies reported an alarmingly high incidence of gallstones in diabetics as compared with general population and in view of profound morbidity and mortality rates observed in the diabetics, prophylactic cholecystectomy was generally recommended. However, recent evidence-based studies challenged this approach and have concluded that prophylactic cholecystectomy is not justified in diabetic patients with asymptomatic gallstones. It is inferred that, as in general population, asymptomatic cholelithiasis in diabetics should be managed expectantly and preemptive surgery should not be routinely performed. However, early laparoscopic cholecystectomy is preferred in cases of symptomatic cholelithiasis.

Key Words: Cholelithiasis, Asymptomatic gallstones, Diabetes mellitus.

In the western world the prevalence of gallstone disease varies from $7 \%$ to $18 \%$ in males and $8 \%$ to $23 \%$ in females ${ }^{1-5}$. At least two- thirds of the gallstone carriers are asymptomatic and most of them are unaware of the presence of their gallstones ${ }^{2,3}, 4$. There is a general consensus on the view that asymptomatic cholelithiasis should be managed expectantly ${ }^{6}$. This approach is consistent with the results of follow-up studies on the natural history of silent stones showing a benign course of the disease ${ }^{7}$. However, no controlled clinical trials have been carried out as yet in the diabetic patients with gallstones $^{8}$. The management of cholelithiasis in patients with diabetes is controversial ${ }^{9}$. Early retospective and autopsy studies reported a dramatically higher prevalence of gallstones in the diabetics as well as a significantly greater morbidity and mortality of cholelithiasis when compared with general population ${ }^{10,11}$. Recent reports in medical literature have been reflective of improved perioperative care for co-morbid illnesses and have challenged this traditional view ${ }^{12}$. These studies suggest that the prevalence of cholelithiasis and the outcome of cholecystectomy are similar in diabetics as compared with the well population ${ }^{13,14}$.

The purpose of this paper is to help formulate a strategy about the management of cholelithiasis in the diabetics. This is a critical review of the risks and benefits of the therapy for the gallstone disease in the diabetic patients who are considering treatment to prevent further episodes of biliary pain or its complications. The incidence, natural history of gallstone disease and various therapeutic options are discussed.
Incidence and Natural History of Cholelithiasis in Diabetics

Approximately 15-20 million adults in the United States have gallstones, most of which are asymptomatic 15.16 . While symptomatic gallbladder disease is an accepted indication for surgery, more recent research disclose that only $10-18 \%$ of asymptomatic patients ever develop symptoms ${ }^{17}$. When symptoms do supervene, they usually begin as non-life threatening biliary colic within five years of the original diagnosis ${ }^{18}$. This observation holds true for the diabetics as well as the general population. Diabetes mellitus is often mentioned as an independent risk factor for the development of cholelithiasis ${ }^{19}$. The prevalence of gallstones by autopsy in diabetics has been reported to be as high as $30.2 \%$, compared with $11.6 \%$ in non diabetics in a prospective study conducted on diabetics ${ }^{19}$. Similarly, in a survey of 691 patients in a health maintenance organization in the United States diabetes mellitus was present in $30 \%$ of those with asymptomatic cholelithiasis 20 . However, population-based research in Italy $^{21}$, Denmark $^{22}$ and $\operatorname{Japan}^{23}$ as well as a recent case-control study from Sweden ${ }^{24}$ have not corroborated these observations. At the same time, diabetes is associated with both obesity and type IV hyperlipidemia which are established risk factors for cholelithiasis ${ }^{23,24}$ and may confound the effect of diabetes mellitus.

If an increased risk of cholelithiasis in diabetics does exist, the pathogenic mechanism is largely unknown. Biliary stasis may contribute to the risk of gallstones in diabetics. Gallbladder emptying in response to cholecystokinin infusion measured by radionuclide 
cholescintigraphy was reduced by $25 \%$ in the diabetics compared with the healthy controls ${ }^{25}$. The reduction was much more evident in patients with stigma of autonomic neuropathy reflecting a neurally mediated mechanism. Once formed, gallstones rarely disappear spontaneously. An exception is the stones formed during the metabolic disturbances that accompany weight reduction 26 or pregnancy which may spontaneously disappear ${ }^{27}$. Once present, gallstones may lead to biliary pain or complications like acute cholecystitis, perforation or emphysematous cholecystitis ${ }^{28}$. Gracie et al ${ }^{7}$ have concluded in their study that the rate to develop biliary pain is about $2 \%$ per year for five years and then may decrease over time. Similarly, Friedman and colleagues ${ }^{29}$ reported an incidence of 3-4\% per year for "any [biliary] event" during the first ten years of follow-up. These events consist of biliary colic, biliary complications and "cholecystectomy" for chronic or milder symptoms. The rate decreased to $1-2 \%$ per year during the next 10 years. Data from Newman et al ${ }^{30}$ can be interpreted to show a $19 \%$ cumulative probability to develop over ten years or approximately $2.2 \%$ per year. Several other studies have convincingly showed that asymptomatic gallstones in the well population rarely lead to life-threatening complications, and therefore the risk and expense of surgery far outweigh the benefit ${ }^{31.32}$.

The issue of application of these findings to the patients with diabetes needs to be addressed. Gracie and Ransohoff ${ }^{33}$ studied 123 diabetic faculty members with gallstone disease at the University of Michigan [male:female ratio, 1:8.5] and reported no mortality for initially asymptomatic gallstones over twenty years of follow-up. This study revealed that the rate of progression from asymptomatic to symptomatic disease was lower than previously reported: $10 \%$ at five years, $15 \%$ at ten years and $18 \%$ at 20 years. Because most of the initial presentations of cholelithiasis consisted of uncomplicated biliary pain, only $1.6 \%$ of those subjects followed-up required urgent cholecystectomy, a procedure associated with a much higher operative risk than elective cholecystectomy.

In the National Cooperative Gallstone Study ${ }^{34}, 305$ patients with gallstones, of whom 16 were diabetic, were followed up prospectively for two years. Among 193 asymptomatic patients, 31\% developed biliary colic as opposed to $59 \%$ cases with no complaints. There was no difference in the incidence of biliary pain among the 16 diabetic patients compared with the non diabetics. This report further substantiates the view that diabetes in not an independent risk factor in the pathogenesis of cholelithiasis.

\section{Complications of Cholelithiasis in Diabetics}

Many health problems have been associated with gallstone disease including old age, alcoholism, smoking, multiparity and diabetes mellitus ${ }^{35}$. Cholecystitis in the diabetics is a more severe disease as it may present unexpectedly and advance rapidly ${ }^{36}$. This led to a general consensus that prophylactic cholecystectomy should be performed in the diabetic patients with asymptomatic gallstones. More recently, Hickman et al ${ }^{37}$ reported that infectious complications occurred in their study group of 109 diabetics at a rate three times that of non diabetic casecontrols. Moreover, the $4.2 \%$ mortality rate in the diabetics in that study was entirely attributed to sepsis. The incidence of advanced concurrent medical conditions including cardiovascular, renal and pulmonary diseases was $35 \%$ in the diabetic patients and $15 \%$ in non diabetics with the conclusion that any single factor can not be held responsible for the increased morbidity.

More serious complications of cholecystitis like gangrene, perforation and emphysematous cholecystitis are reported to occur in up to $20-40 \%$ of diabetics ${ }^{38}$. These complications necessitate urgent surgical intervention and certainly compound the peri operative risk. Of patients with gallbladder perforations complicating acute cholecystitis, $16 \%$ to $25 \%$ cases were found to have diabetes in a prospective study of 101 patients ${ }^{39}$. Diabetics are at increased risk of developing emphysematous cholecystitis, a rare condition with a 30 -fold increased risk of gangrene and three-fold increase of both perforation and death ${ }^{40}$. There seems to be little correlation between the severity of diabetes and the incidence of complications of acute cholecystitis ${ }^{3}$. Walsh et al ${ }^{41}$ reviewed 80 diabetics with either acute cholecystitis [29 patients] or who had elective cholecystectomy [51 patients] and found no difference in the rates of complications between the diabetics and 95 non diabetic controls. Morbidity was markedly high in the presence of vascular and renal ailments regardless of the diabetic status. Ransohoff and colleagues ${ }^{42}$ studied patients with acute cholecystitis over a twenty years period and observed that death occurred in three of forty six patients with diabetes and in seven of 263 non diabetic controls : a difference which is not statistically remarkable $[p=.55]$. In the same study patients with an elevated blood urea nitrogen level were found to have a significantly higher mortality rate: $27 \%$ compared with $2 \%$ in patients without renal impairment. This study reaffirms the finding that renal and vascular complications contribute to the increased risk of biliary tract disease than diabetes alone.

\section{Treatment Options for Gallstone Disease in Diabetics}

There are three basic therapeutic approaches for cholelithiasis in the diabetic and non diabetic subjects: expectant, non surgical and surgical intervention. Expectant management, defined as therapeutic intervention delayed until gallstone symptoms or complications spontaneously develop, involves the trade-off between the benefit of possibly avoiding an intervention versus risk of inducing known possible complications of the surgical procedure itself ${ }^{43}$. The non surgical approach involves the 
removal of gallstones but not the gallbladder. The options mclude oral dissolution therapy with bile acids, extra corporeal shock wave lithotripsy [ESWL] and contact dissolution with methyl ter butyl ether ${ }^{44}$. Walters and colleagues $^{45}$ have concluded in their study of 134 cases with asymptomatic gallstones that the awareness of the presence of gallstones leads to prophylactic cholecystectomy in $20 \%$ to $31 \%$ of cases, despite the persistence of asymptomatic state in most of the patients. Oral dissolution therapy can be offered to such patients who want to "get rid of their silent stones" but there is a five year recurrence rate of $50 \%$ following discontinuation of treatment which tends to temper enthusiasm for this modality ${ }^{45}$. ESWL is another non operative method but severe colicky pain secondary to stone fragmentation develops in up to $79 \%$ of cases. Therapy with oral bile acids before and after the procedure is required, adding to a cost that is comparable with surgery. Laparoscopic cholecystectomy has numerous advantages over open version including short hospital stay, less post operative pain, faster return to full activity and better cosmesis ${ }^{40}$. However, patients with asymptomatic gallstones are usually not candidates for laparoscopic cholecystectomy according to the "National Institute of Health Consensus Development Conference Statement on Gallstones and Laparoscopic Cholecystectomy" ${ }^{47}$. The indications for gallbladder removal should not be expanded even if the procedure is less invasive ${ }^{43}$. Furthermore, it has been shown that prophylactic cholecystectomy for silent stones in the diabetics does not appear to increase either the duration or quality of life, but may in fact reduce it ${ }^{49}$.

\section{Conclusion}

Foregoing in view, a major clinical challenge in the management of gallstone disease in the diabetic patients is to identify those who have the highest risk to develop an acute biliary complication: there are currently no good predictors. There is no convincing evidence that diabetes mellitus is an independent risk factor for cholelithiasis. The increased morbidity and mortality in the diabetics with cholecystitis is more often related to the underlying renal and cardiovascular affections independent of diabetes mellitus. Prophylactic cholecystectomy for asymptomatic gallstones is without benefit and using the available analysis based data, routine cholecystectomy for asymptomatic gallstones in the diabetic patients is not recommended. A "watch-and wait" approach is advised for asymptomatic cholelithiasis in the diabetics when found, and surgical therapy when symptoms specific to cholelithiasis ensue.

\section{References}

1. Ghiloni BW. Cholelithiasis: current treatment options. Am Fam Physician; 1993 Oct: 48[5]: 762-8.

2. Rome Group for Epidemiology and Prevention of Cholelithiasis [GREPCO]. Prevalence of gallstone disease in an Italian adult female population. Am J Epidemiol 1984; 119: 796-805.

3. Baruara L, Sama C, Morselli Labate AM. A population study on the prevalence of gallstone disease. The Sirmione study. Hepatology 1987; 7: 913-7.

4. Maurer KR, Everhart JE, Ezzati TM. Prevalence of gallstone disease in Hispanic populations in the United States. Gastroenterology 1989; 96: 487-92.

5. Heaton KW, Braddon Fem, Mauntford RA, Hughes AO, Emmett PM. Symptomatic and silent gallstones.in the community. Gut 1991; 32: 316-20.

6. Schoenfield LJ, Carulli N, Dowling RH, Sama C, Wolpers C. Asymptomatic gallstones: definition and treatment. Gastroenterol Int 1989; 2: 25-9.

7. Gracie WA, Ransohoff DF. The natural history of gallstones. The 'innocent' gallstone is not a myth. N Engl J Med 1982; 307:798-8()0.

8. Mok HYI, Druffel ERM, Rampone WM. Chronology of cholelithiasis. Dating gallstones from atmospheric radiocarbon produced by nuclear bomb explosions. $N$ Eng $J$ Med 1986; 314: 1075-7.

9. Meshikhes AW. Asymptomatic gallstones in the laparoscopic era. J R Coll Edinb 2002; 47[6]: 742-748.

10. Ponte E, Pinebianco A, Morena S. Diabetic ncuropathy. Minerva Med 1990; 81:335-40.

11. David F, Ransohoff MD, William A, Gracie MD Treatment of gallstones. Ann Intern Med 1993;119: 606619.

12. Ikard RW. Gallstones, cholecystitis and diabetes. Surg Gynecol Obstet; 1990; 171: 528-32.

13. Ancott JN, Cooper GS, Bloom AD, Aron DC. Management of gallstones in the diabetic patients. Arch Int Med 1993; 153: 1053-58.

14. Batineau TJ, Booth A Jr. General surgery indications in the diabetic patients. Infect Dis Clin North Am 1995; 9:183-93.

15. Marshall JB .Current options in gallstone management: what to do when symptoms are mild or absent. Postgrad Med 1994; 95:115-120.

16. Heaton $\mathrm{KW}$, Braddon FE, Mountford RA, Hughes AO, Emmett PM. Symptomatic and silent gallstones in the community. Gut 1991; 32:316-320.

17. Braunwald E, Isselbacher KJ, Petersdorf RG, Wilson JD, Martin JB et al. Harrison's Principles of Internal Medicine, $11^{\text {th }}$ ed. New York, NY: McGraw-Hill Book Co; 1987 1359-1366.

18. Ransohoff DF, Gracie WA. Treatment of gallstones. Ann Int Med 1993; 119:606-619.

19. Haffner SM, Diehl AK, Mitchell BD, Stern MP, Hazuda HP Increased prevalence of gallbladder disease in subjects with non-insulin dependent diabetes mellitus. Am J Epedemiol 1990; 132: 327-335.

20. McSherry CK, Ferstenberg H, Calhoun WF, Lahman E, Virshup M. The natural history of diagnosed gallstone disease in symptomatic and asymptomatic patients. Ann Surg 1985; 202: 59-63.

21. The Rome Group for Epidemiology and prevention of cholelithiasis [GREPCO]. The epidemiology of gallstonc disease in Rome, Italy: factors associated with the disease. Hepatology 1988; 8: 907-913

22. Jorgensen T. Gallstones in a Danish population: relation to weight, physical activity, smoking, coffee consumption and diabetes mellitus. Gut 1989; 30:528-534. 
23. Kono S, Kochi S, Wakisaka A. Gallstones, serum lipids and glucose tolerance among male officials of self- defense forces in Japan. Dig Dis Sci 1988; 33: 839-844.

24. Persson GE, Thulin AJG. Prevalence of gallstone disease in patients with diabetes mellitus: a case control study. Eu J Surg 1991; 157: 579-582.

25. Stone BJ, Gavaler JS, Belle SH. Impairment of gallbladder emptyıng in diabetes mellitus. Gastroenterol 1988; 95:170-6.

26. Yang H, Petersen GM, Roth MP, Schoenfield LJ, Marks JW. Risk factors for gallbladder formation during rapid loss of weight. Dig Dis Sci 1992; 37: 912-8.

27. Maringhini A, Ciambra $M$, Baccelliere $P$, Raimondo $M$, Grasso R. Incidence and natural history of gallbladder sludge and stones during and after pregnancy: a prospective study. Hepatology 1990; 12: 900.

28. Zubler J, Markowski G, Yale S, Graham R Rosenthal TC. Natural history of asymptomatic gallstones in family practice office practices. Arch Fam Med 1998; 7: 230-3.

29. Fricdman GD, Raviola CA, Fireman B. Prognosis of gallstones with mild or no symptoms: 25 years of follow-up in a health maintenance organization. J Clin Epidemiol 1989:42:127-36.

30. Newman DM, Detsky AS. The meaning of life expectancy: what is a clinically significant gain? Med Decision Making 1992; 12: 344

31. Fendrick AM, Gleeson SP, Cabana MD, Schwartz JS. Asymptomatic gallstones revisited .Is there a role of laparoscopic cholecystectomy? Arch Fam Med 1993; 2[9]: 95)-68.

32. Coelho JC, Vizzito AO, Salvalaggio,PR, Tolazzi AR. Laparoscopic cholecystectomy to treat patients with asymptomatic gallctones. Dig Surg 2000; 17[4]: 344 -7.

33. Gracie WA, Ransohoff DA. The natural history of silent of gailstones. N Eng J Med 1982; 307:798-800.

34. Diehl AK. Epidemiology and natural history of gallstone disease. Gastroenterol Clin North Am 1991; 20:1-19.

35. Gibney EJ. Asymptomatic gallstones. Br J Surg 1990; $77: 368-72$

36. Pattison AC,Turrill FL, McCarron MM, Mikkelsen WP. Gallstone and diabetes: an ominous association. Am J Surg 1961:102:184-19().
37. Hickman MS, Schwesinger WH, Page CP. Acute cholecystitis in the diabetic. Arch Surg 1988;123: 409-11.

38. Schien CJ. Acute cholecystitis in the diabetics. Am J Gastroenterol 1969; 51: 511-515.

39. Sandler RS, Maule WF, Baltus ME. Factors associated with postoperative complications in diabetics after biliary tract surgery. Gastroenterology 1986; 91:157-162.

40. Roslynn JJ, Thompson JE Jr., Darvin H, Den Besten L. Risk factors for gallbladder perforation. Am J Gastroenterol 1987; 82: 636-640.

41. Walsh DB, Eckhauser FE, Ramsburgh SR, Burney RB. Risk associated with diabetes mellitus in patients undergoing gallbladder surgery. Surgery 1992; 91: 254-257.

42. Ransohoff DF, Miller GL, Forsythe SB, Hermann RE. Outcome of acute cholecystitis in patients with diabetes mellitus. Am Int Med 1987; 106:829-832.

43. Marshall JB. Current options in gallbladder management. What to do when symptoms are mild or absent. Postgrad Med 1994; 95[5]: 115-121.

44. Gleeson D, Ruppin DC, Saunders A, Murphy GM, Dowling RH. Final outcome of Ursodeoxy cholic acid treatment in 126 patients with radiolucent stones. Q J Med 1990; 76: 711-29.

45. Walters JRF, Hood KA, Glecson $P$ et al. Combination therapy with oral UDCA and chenodeoxycholic acids: pretreatment computed tomography of the gallbladder improves gallstones dissolution efficacy. Gut 1992; 33: 37580 .

46. Schwesinger WH, Diehl AK. Changing indications for laparoscopic cholecystectomy. Stones without symptoms and symptoms without stones. Surg Clin North Am 1996; 76: 493-504.

47. National Institute of Health [1993]. National Institutes of Health Consensus Development Conference Statement on gallstones and laparoscopic cholecystectomy. Am J Surg 1993; 390-398.

48. Watson DI, Mathew JA. Impact of laparoscopic cholecystectomy in a major teaching hospital: clinical and hospital outcomes. Med J Aust 1995; 163:527-530.

49. Aranjo LM, DeOlivera DA, Nunes DS. Liver and biliary ultrasonography in diabetic and non diabetic patients: a decision analysis. Diabetes Metabol 1998; 24: 458-62. 